\title{
Automation and Electronic Control of Marine Gas Turbine Engine for Ship Revamp
}

\author{
Filip Niculescu \\ Romanian Research and Development Institute for Gas Turbines COMOTI \\ filip.niculescu@comoti.ro \\ Claudia Borzea \\ Romanian Research and Development Institute for Gas Turbines COMOTI \\ claudia.borzea@comoti.ro
}

\section{Adrian Savescu}

Romanian Research and Development Institute for Gas Turbines COMOTI adrian.savescu@,comoti.ro

\section{Andrei Mitru}

Romanian Research and Development Institute for Gas Turbines COMOTI andrei.mitru@,comoti.ro

\section{Mirela Letitia Vasile}

Romanian Research and Development Institute for Gas Turbines COMOTI mirela.vasile@comoti.ro

\begin{abstract}
Gas turbines used in propulsion ensure increased efficiency and safety, with a very good power / weight ratio and with low maintenance and operation costs. Due to becoming out-of-date and reaching the maximum operation hours and expected lifetime, which can cause malfunctioning, older turbine engines on frigates need to be replaced with newer generation propulsion engines. The paper presents the replacement of the turbine engine on a defence frigate, focusing on the automation and electronic control solution employed for a propulsion turbine, integrating state-of-the-art techniques. The electronic system ensures control, monitoring and alarm functions, including overspeed protection. A local control panel interfacing the PLC displays the operating parameters and engine controls, also providing maintenance and calibration sequences. The proposed solution enables both the local and the remote control of the ship's gas turbine.
\end{abstract}

Keywords. turbines, control, marine technology, automation, command and control systems. 


\section{Introduction}

Gas turbine engines experience degradations over time that cause great concern regarding engine reliability, availability and operating costs [1-3]. Therefore, after becoming out-of-date and at some moment beginning to be unreliable for the precision required in marine ships, these engines need to be replaced. Choosing a propulsion system for maritime applications supposes the integration of a large number of elements into a limited functional space, choosing its components (propulsion engine, gear transmission and thruster), and adjusting them according to the imposed constraints and available space, as well as arranging the components in such a configuration so as to comply with the required performance [4].

A marine propulsion system's purpose is to convert a primary form of energy into mechanical power, and to convey this one to the propulsion, in order to ensure the necessary torque for driving the propeller. The gas turbine power should be enough to overcome the inertia of ship's advancement in order to set it on the desired direction and at the required speed. From energetic point of view, a marine propulsion system consists of the power source (main propulsion engine) and the energy consumer (thruster). Among the currently used marine thrusters, propellers best cater for the current naval technology, being the most frequently used and generally the most efficient type of marine propulsion [4].

The paper presents the replacement of an out-of-date maritime turbine engine, which is no longer reliable, with a modern propulsion system. The power of the new system, Pratt\&Whitney ST40M, is the same as the one of the old engine, Rolls Royce Tyne [5], namely 4 MW. However, after the last capital revision of the Tyne engine, the maximum power obtained was less than $3 \mathrm{MW}$.

ST40M is currently being used only on the series of Norwegian large, superfast, stealth missile corvettes Skjold, using 4 gas turbines combined by Renk COGAG gear units in lightweight design. Each gas turbine propulsion system features two $2000 \mathrm{~kW}$ ST18M marine gas turbines (for cruise speed) and two $6000 \mathrm{~kW} \mathrm{ST40M} \mathrm{marine} \mathrm{gas} \mathrm{turbines} \mathrm{(for} \mathrm{sprint} \mathrm{speed).}$

The ST18M and ST40M are free turbine turboshaft engines derived from Pratt \& Whitney Canada's PW100 and PW150A aviation turboprop power plants respectively, which are recognized as the aviation industry benchmark for reliability and operating economics. The gas turbines have been tailored for marine applications and offer high efficiency and low weight capabilities [6].

ST18 engines are currently being used for cogeneration purposes, at Suplacu de Barcău power plant, installed and commissioned by Romanian Research and Development Institute for Gas Turbines - INCDT COMOTI. The power plant was built with the aim of studying the efficiency in growing oil production with lower costs for the electrical and thermal energy used in oil field. Each line consists of an electrical turbogenerator powered by one aero derivative ST18 Pratt\&Whitney turbine engine, a Heat Recovery Steam Generator (HRSG) with afterburner, and linked installations. The ST18M proved its efficiency and reliability, providing 32,000 hours between overhauls. Operating over 55,000 hours from 2004 to 2008, the two lines of the cogeneration plant provided an efficiency of $85 \%$. [7]

\section{Marine gas turbine replacement}

Pratt\&Whitney delivers ST40M engine (Figure 1) without the control electronics. For being able to operate as cruise engine, this one has to be adapted to the specific type of ship. The frigate uses two ST40M engines for cruise speed, and two Rolls Royce Olympus gas turbines for sprint speed. 




Fig. 1. Section through the model of ST40M gas turbine engine

In our case, for the frigates, the necessary adaptations suppose:

- Start-up with pneumatic starter, controlled by the local automated control and command system;

- Adapting the inlet and outlet of ST40M engine to the admission and evacuation of the frigate;

- Fastening the engine on the frigate with the current supports of the frigate and developing the necessary high accuracy flanges for adapting to the current mounting supports, as well as developing a centering flange;

- Adapting the oil and fuel systems of the ship for ST40M gas turbine engine;

- Developing an automated electronic system for the remote control of the engine.

These adaptations are necessary so that the gas turbine engine to operate as much as possible accordingly to the performance curves provided in engine specifications given by the manufacturer (Figure 2 hereinafter).
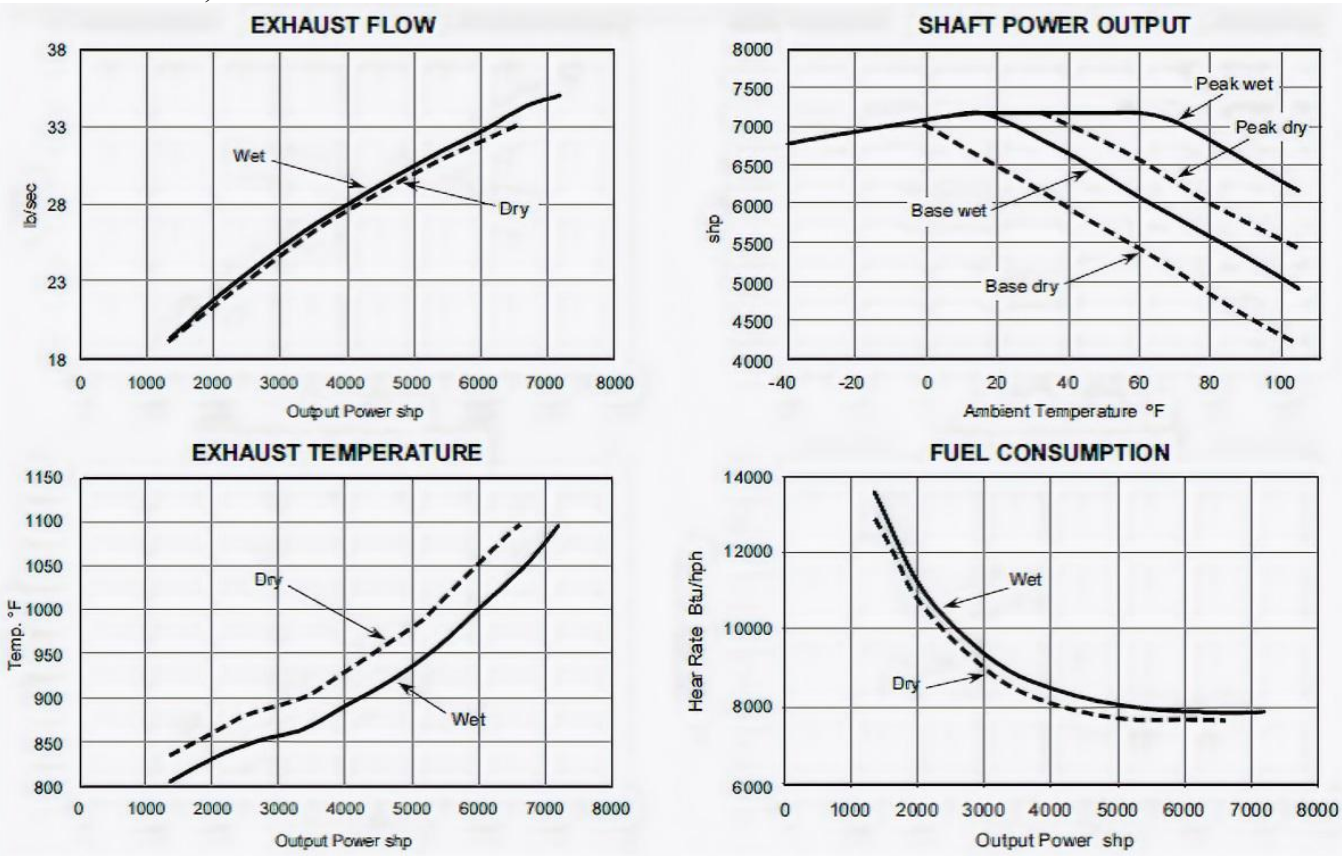

Fig. 2. Performance curves of ST40M gas turbine engine 


\section{Automation and electronic control system design}

The advantages of electronic controls in terms of accuracy and adaptability to various differing requirements have been recognized for a long time [8]. Among the available control systems [9], the electronic control currently offers the highest reliability and adaptability, and can easily and rapidly be tailored for any arising situation or parameter change $[10,11]$. An automated electronic control system (AECS) was designed, built, installed and tested together with the ST40 engine to replace the old propulsion system.

The gas turbine control is performed from the engines control room of the ship, situated on the deck above the hull, where the four engines are situated for ensuring the propulsion of the frigate. The turbine engines command is realized from the touchscreen local control panel interfacing the PLC, which takes the human operator's command, analyses the exact cruise situation of the ship, the regimes of the other propulsion systems, and conveys the electronic command to the PLC, that triggers the actuation elements for driving the engines. The PLC also monitors and acquires the parameters for the operation in optimum conditions, and setting thresholds for a safe and secure operation.

In the design and development phase, INCDT COMOTI has defined the requirements of the automated electronic system. AECS was designed and was physically implemented, as well as tested, in order to evaluate system's performances. The tests included an offline signals simulation followed by a set of tests with AECS connected to the engine on the test bench.

In the design and development phase, a team of engineers from several disciplines has defined the requirements of AECS. The system was designed, implemented physically, as well as tested in order to evaluate system's performances.

Using replaceable hardware modules that proved reliable in other applications facilitates system maintenance in the event of a fault, and the timely replacement of the modules. Unexpected changes to the system or operation parameters can be easily accomplished by changing the program implemented in the PLC software.

For the engine control system, the specific FADEC (Full Authority Digital Engine Control) system used in other applications was replaced with a local control panel fulfilling the same functions. The block diagram of the system is shown in Figure 3 below.

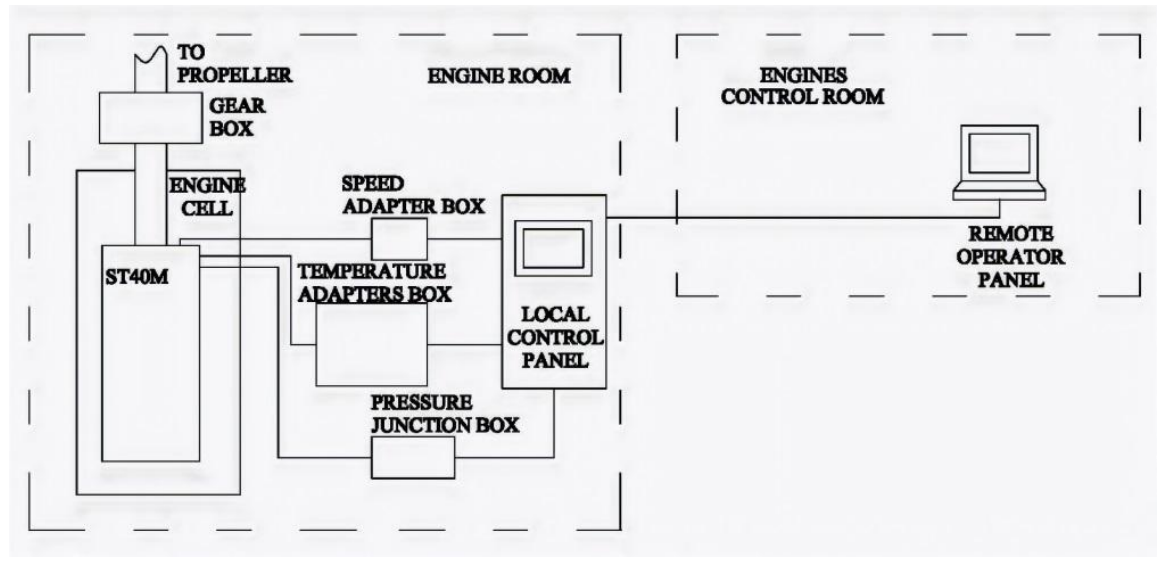

Fig. 3. Block diagram of ST40M implementation

The General Electric VersaMax PLC chosen for the engine control system consists of: CPU (Central Processing Unit), power supply 24 VDC unit, 15 channels and 8 channels modules for analogue inputs, 4 channels analogue outputs module, 32 digital inputs module and 32 digital outputs module (Figure 4). The PLC assembly located in the local control cabinet is connected to the current adapters located in the junction boxes in the close proximity of the engine. 




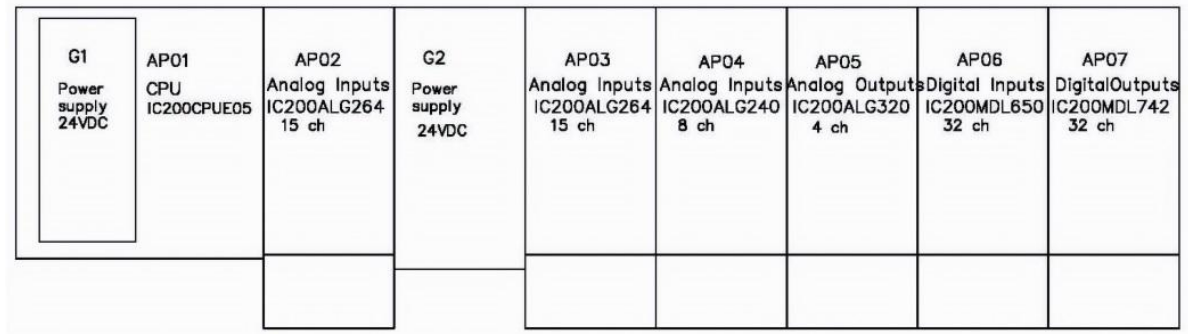

Fig. 4. PLC configuration layout

The CPU communicates over Ethernet with the operator panel in the local control cabinet and with the computer control in the engine command room. The number of tests to validate the project using hardware used in other applications where it has proved its reliability has been evaluated at a fraction of that required for a different control system. This has led to a low implementation cost and the ability to quickly change design if a need to change the parameters arises.

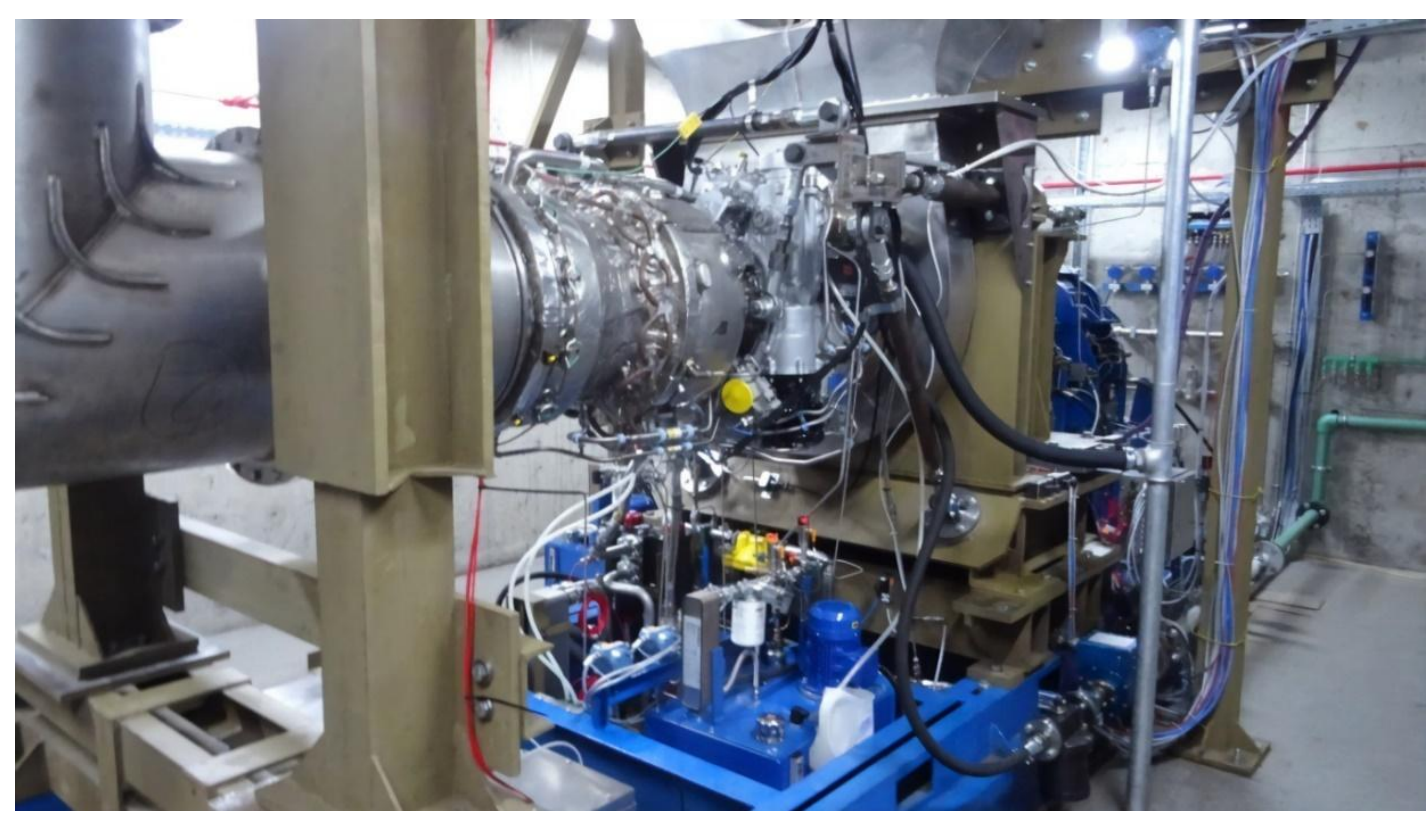

Fig. 5. The ST40M gas turbine on the test bench 
Bench tests of the engine with the AECS system were comparable to those performed by the engine manufacturer. The ST40M engine was installed on the turbine bench at INCDT COMOTI headquarters (Figure 5 above). The gas turbine engine passed successfully the performance tests provided by the manufacturer, in our desired configuration.

The configuration in which the transducers are placed was established considering the distance from the measured parameter, the ease of debugging, as well as choosing the optimal spots so as to minimize the environmental influences on the device (such as a possible penetration of salt water inside the ship, humidity, ambient temperature and pressure, etc.).

On the diagram in Figure 6, the following parameters abbreviations are used: PAST - Air starter pressure; PDUM - Engine differential oil pressure; P3 - Engine compressor pressure; PCM - Engine fuel pressure; PUAX - Oil pressure of torque transmission; PDG - Exhaust gases differential pressure.

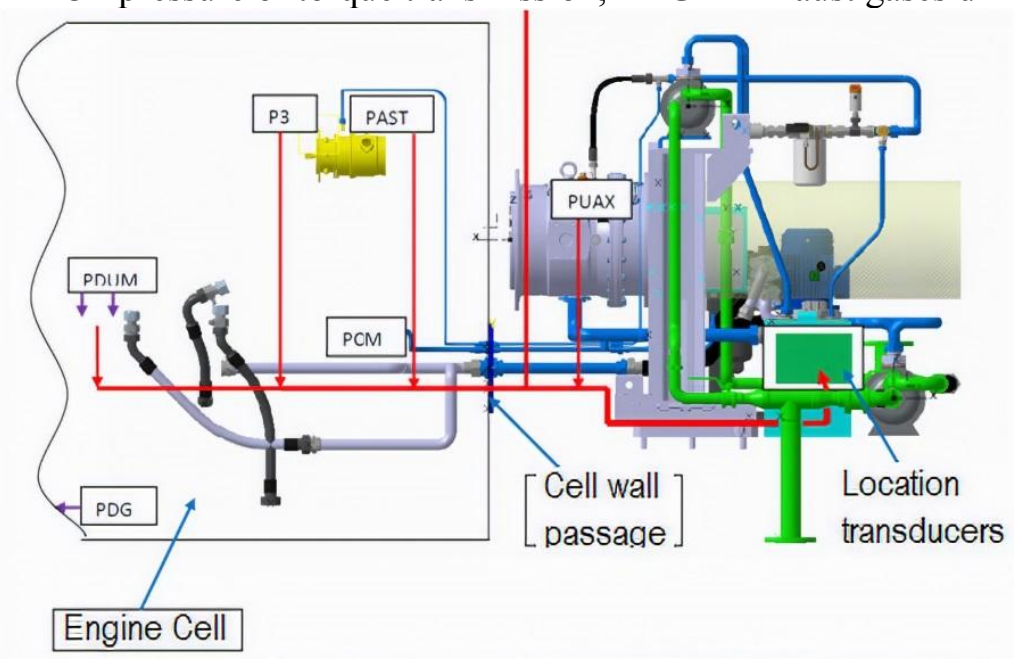

Fig. 6. Parameters measuring spots diagram

Figure 7 shows the local and remote engine control panels during operation. The remote control of the engine is performed by means of a touch panel mounted in the engine control room. The parameters displayed on the two panels are the same, but the display layout is different, being configured in two in different softwares (Proficy machine edition from General Electric for local panel, and Visu+ from Phoenix Contact for the remote control panel).
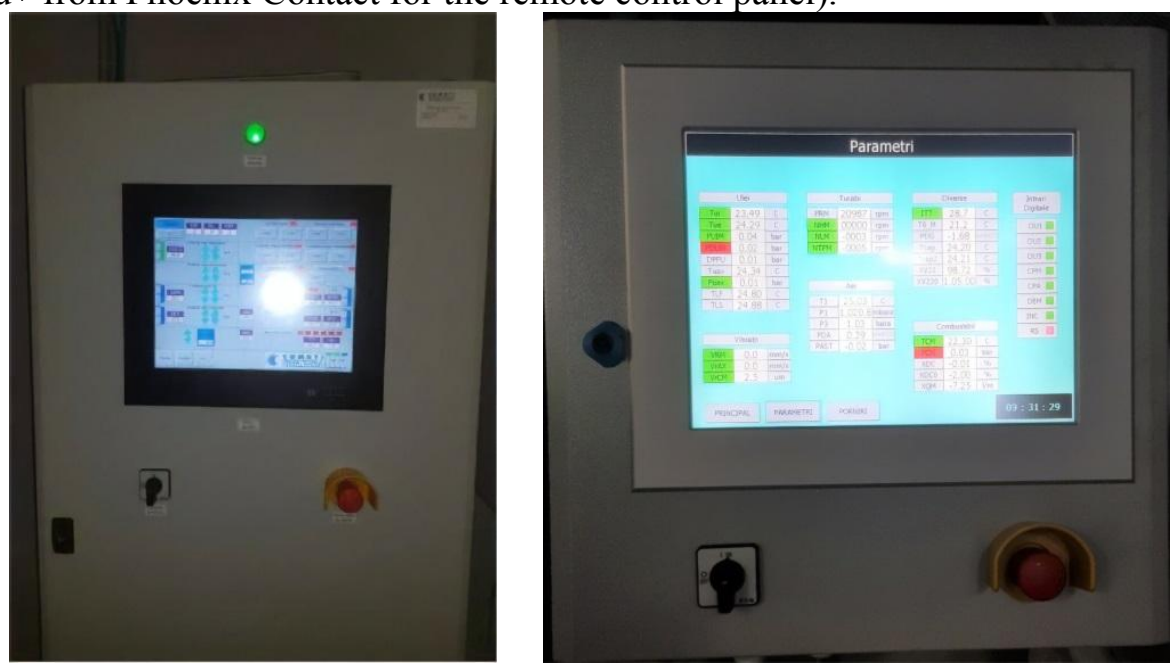

Fig. 7. Local engine control panel (left) and Remote control panel (right) 
Comparing to the old system, the new automated electronic system allows integrated engine control and supervision in a modern solution (with PLC). Engine data is saved and data protection is realised in real time. The PLC implemented software program fulfils the following functions: commands the start-up sequence of the pneumatic starter; commands the gas turbine fuel distributor for ensuring the start-up and reaching idle speed; controls the engine's operation in load conditions, according to its specific performance curves (see Figure 2); ensures the operational limits conditions of the turbine engine and the corresponding warnings and alarms.

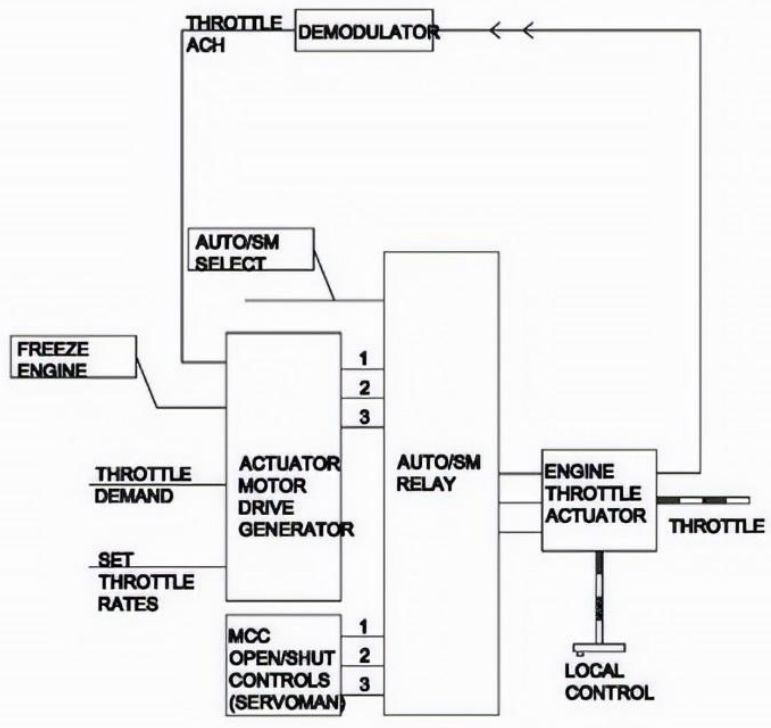

Fig. 8. Engine control system

The tests performed on the ship involved a minimal intervention in the automatic control of engines and propellers. The throttle controlling the power of the old engine was used for the new engine so that this signal is acquired, and depending on it, the engine provides the necessary power to the ship (up to around 3.5 MW). The diagram with the throttle signal which was converted into a direct current signal for the AECS system is shown in Figure 8 above.

The high pressure compressor signal, which represents the throttle position, is converted into a unified 4-20mA signal by the pressure transducer. Its value is converted, by the implemented software program of the PLC, into the corresponding speed of the high pressure compressor required for the ST40M gas turbine. Relying on this signal, the position or opening of the fuel valve is regulated automatically, for setting the desired speed of the ship.

The parameters screen displayed on the local control panel is presented in Figure 9. On this screen, the parameters meanings are: Pornire Calda - Hot start-up; PUAX - Shaft oil pressure; PRM Throttle pressure signal; Maneta - lever; Turatie elice - propeller speed; NHM - Speed of high pressure compressor; $N L M$ - Speed of low pressure compressor; $N T P M$ - speed of the power turbine; Tui - Inlet oil temperature; Tue - Outlet oil temperature; $N L C$ - speed of low pressure compressor; $I T T$ - Calculated Inter Turbine Temperature; T6 $M$ - measured gas temperature after turbine; $X D C$ Position of fuel metering valve; $X V 2.2$ - Position of bleed valve; $P 3$ - compressor pressure; $X V 220 M$ - Imposed position of bleed valve; PV27 - Command signal open/close of bleed valve 2; T1 - air temperature at engine inlet; $V r M$ - engine vibrations; $\operatorname{VrAX}$ - shaft vibrations; $\operatorname{VrCM}$ - shaft vibrations measured with proximity transducer; $P D U M$ - engine oil differential pressure; $P C M$ - engine fuel pressure; PUIM - engine oil inlet pressure; TCM - engine fuel temperature; Tuax - shaft lube oil 
temperature; Puax - shaft lube oil pressure; $T L F$ - front bearing temperature; $T L S$ - rear bearing temperature; PAST - starter air pressure; XDC/P3 - Ratio XDC/P3; NHref - Reference imposed speed; 3 minute pornire -3 minutes start-up; 5 minute oprire -5 minutes stop.

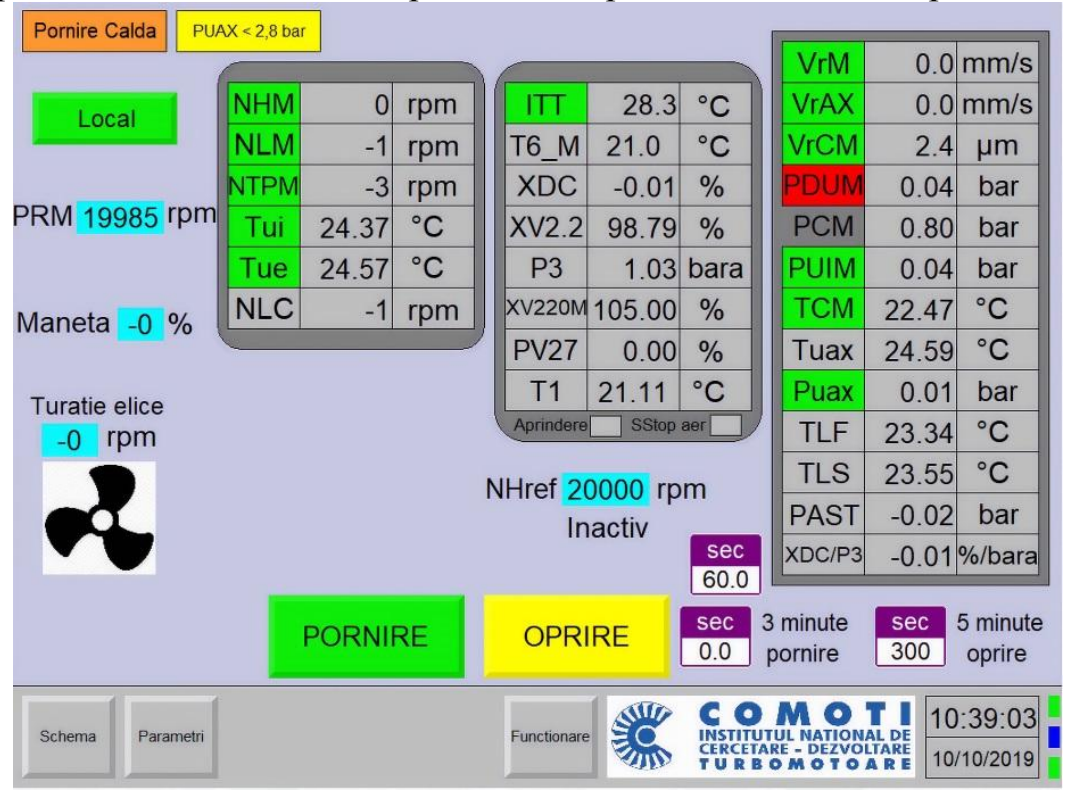

Fig. 9. Engine hot start screen

The graphs in the figures hereinafter have been represented using the acquired parameter values.

From the graph in Figure 10 below, it can be observed that, during tests, the engine reached a speed of between $\sim 22,000 \mathrm{rpm}$ and maximum of $\sim 28,800 \mathrm{rpm}$, which, alone used, drives the ship up to a cruise speed of 8 knots $(\sim 22 \mathrm{~km} / \mathrm{h})$. In the measuring interval, the speed has maintained constant around $28,500 \mathrm{rpm}$.

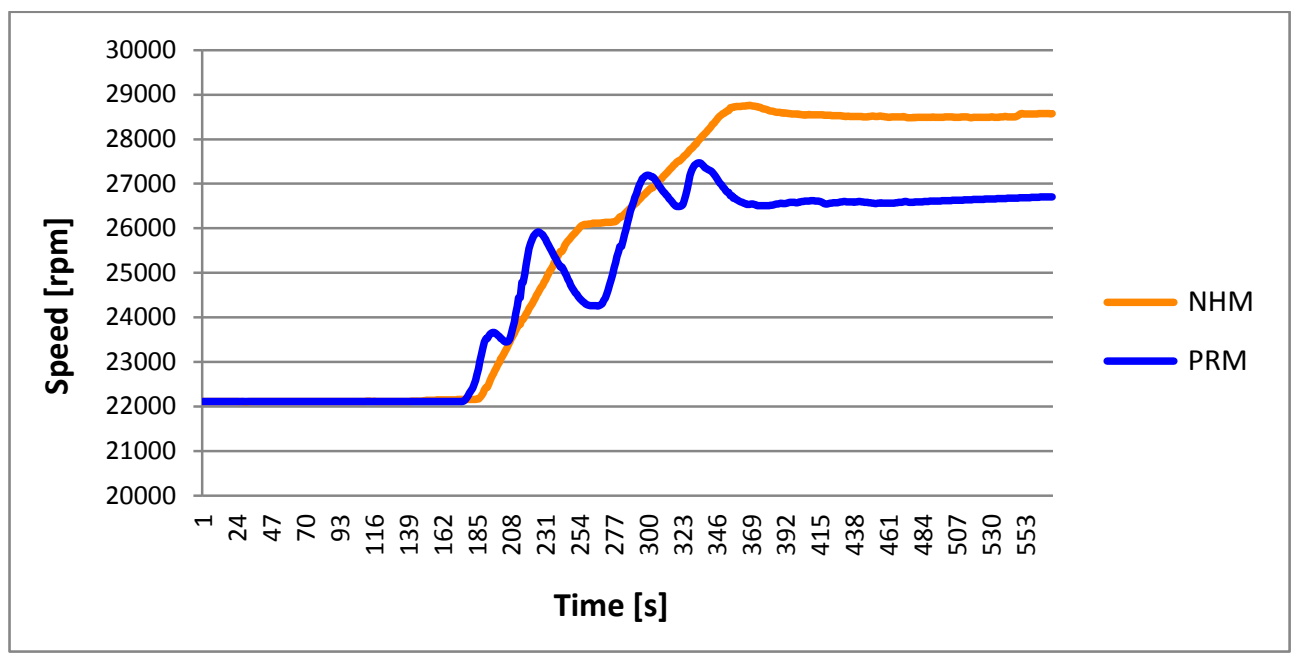

Fig. 10. Evolution of NHM - Speed of high pressure compressor and PRM - Throttle pressure signal 
The inter turbine temperature parameter is considered to be at least $800^{\circ} \mathrm{C}$ by fuel flow decrease condition $\left(\right.$ ITTlim $=800^{\circ} \mathrm{C}$ ). At every time increment $\Delta \mathrm{t}=0.4 \mathrm{sec}$, it is checked that ITT $>800^{\circ} \mathrm{C}$. If this condition is met, it is calculated:

$$
\begin{gathered}
I T T_{\text {lim }}-\operatorname{ITT}\left[{ }^{\circ} \mathrm{C}\right] \\
\Delta X D C C=0.2 \times \Delta I T T[\%] \\
X D C 0=X D C_{n-1}+\Delta X D C C[\%]
\end{gathered}
$$

where: $X D C 0$ - Zero setting position of the fuel metering valve; $X D C n-1$ - Previous increment value of the fuel metering valve position.

The evolution of the inter turbine temperature is presented in the graph in Figure 11.

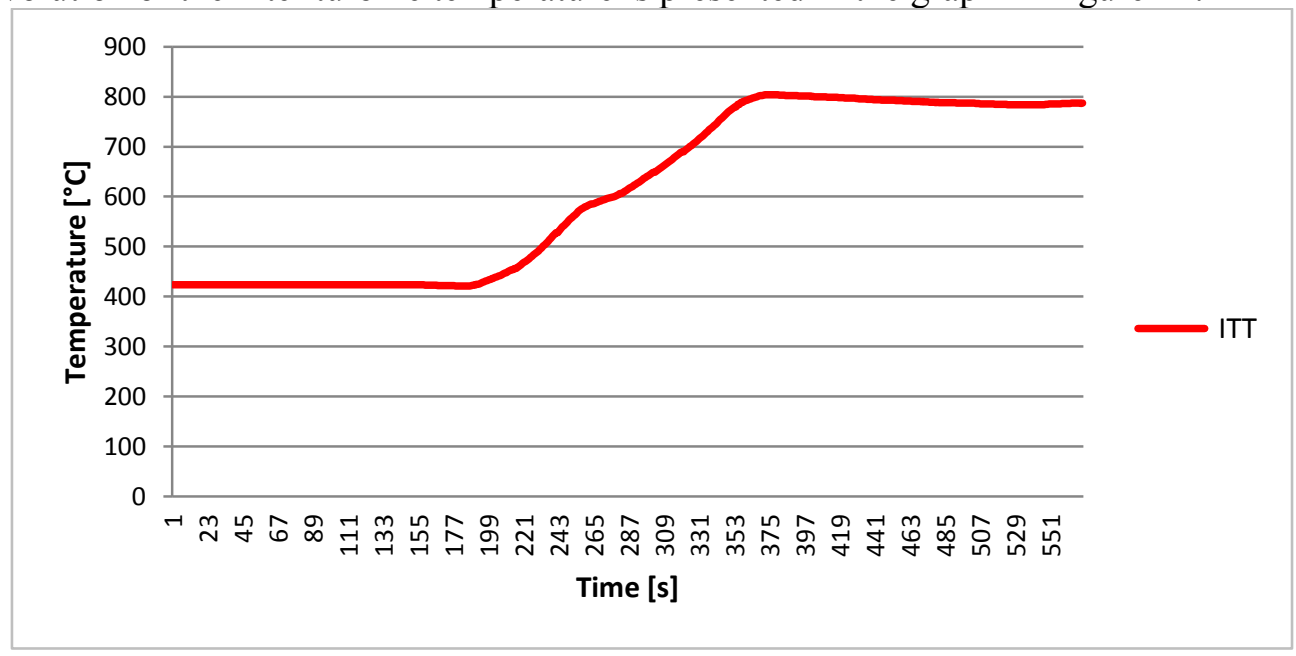

Fig. 11. Evolution of ITT - Inter Turbine Temperature

The graph in Figure 12 shows the opening positions of the fuel metering valve and bleed valve. The $\mathrm{XDC}$ signal corresponding to the fuel metering valve shows that above signifies that the valve is open at $\sim 35 \%$ at idling, increases proportionally with the turbine speed $(\mathrm{NH})$, and reaches a maximum opening of $\sim 82-85 \%$ when the engine reaches the maximum speed of $28,800 \mathrm{rpm}$. The bleed valve (parameter XV2.2) is fully open at idle speed, and closes depending on the speed of the low pressure compressor (NLC) and, correlated with the inter turbine temperature (ITT), it closes completely up to the point that all the air gets in the combustion chamber, ensuring a maximum engine speed. 


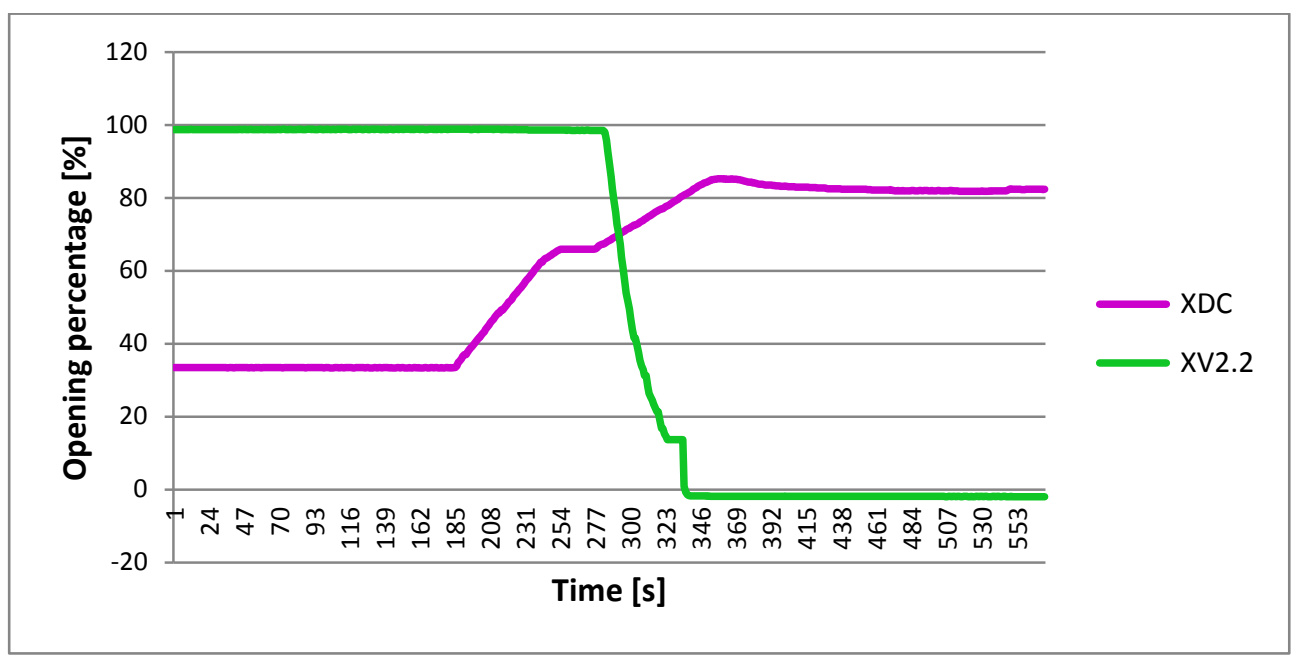

Fig. 12. Evolution of XDC - Fuel metering valve position and XV2.2 - Bleed valve position

Through the control algorithm implemented in the PLC program, the new $X D C_{n}$ position of the fuel valve is controlled according to the prescribed value $X D C O$ of the fuel valve position. From the evolution of inter turbine temperature ITT, a smooth operation of the engine is achieved due to the limitation condition set for this parameter.

Figure 13 shows the main screen with ST40M diagram and its essential parameters, during engine tests on the frigate.

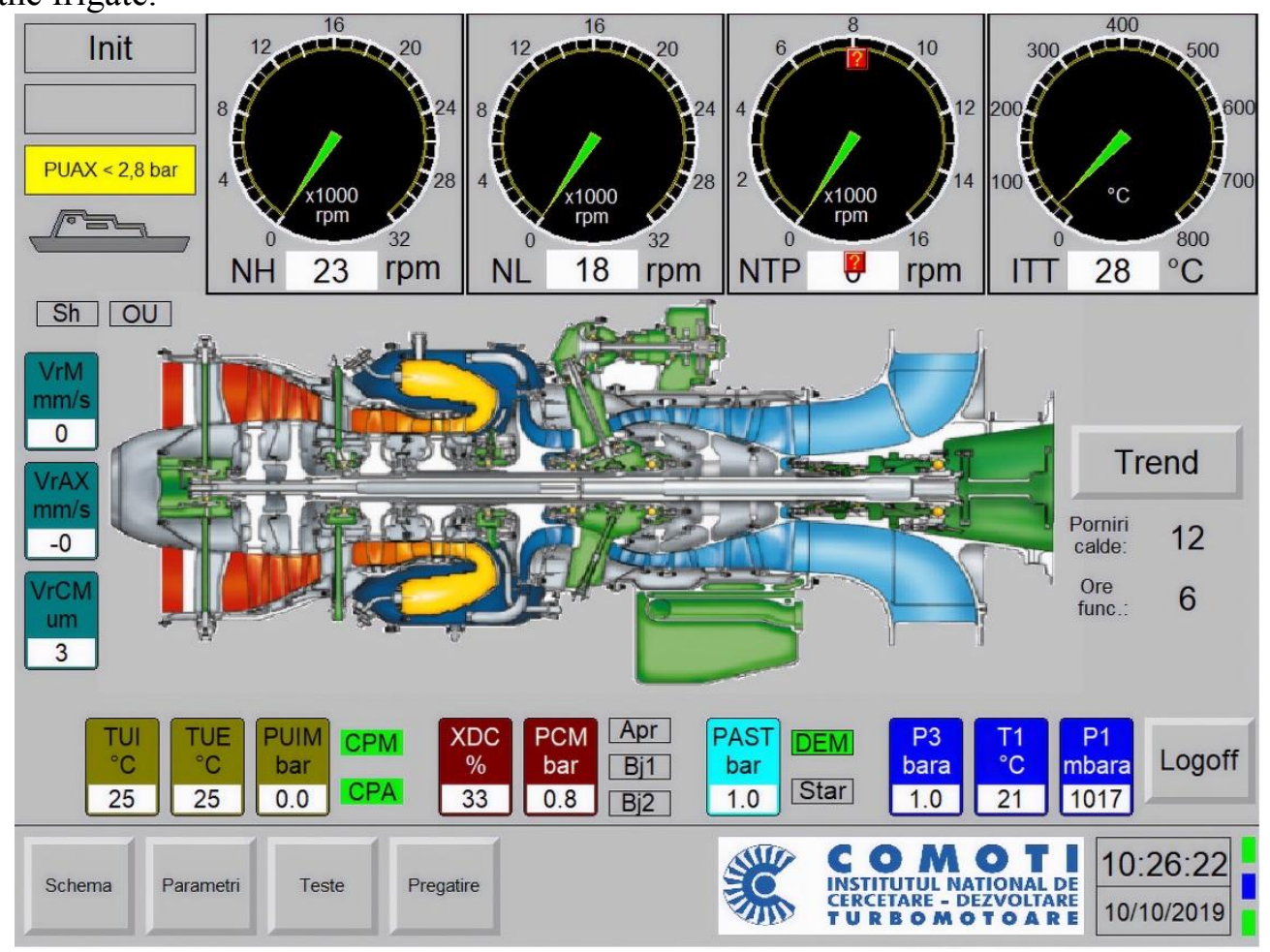

Fig. 13. Main screen displayed on local panel interface

From Figure 11 above it can be observed that the evolution of the essential parameters (speeds, fuel flow, oil temperature and pressure, and exhaust gas temperature), and taking into consideration engine's vibrations, show a good stable behaviour in both no load and loaded operating modes. 


\section{Conclusions}

The evolution of the essential parameters recorded and acquired for ST40M gas turbine engine shows the stability of the engine every operating mode (idle and loaded). The implemented automated electronic control system has proved reliable, accomplishing the optimum control of the gas turbine, with the functions of monitoring, displaying and acquiring of the values of operation parameters. The operation was performed in good conditions and a safe and smooth has been achieved by setting the temperature lower limiting protection. The touchscreen control panels interfacing the PLC provide an easily and safely controlled operation, facilitating the revamp of the frigates by replacing the out-ofdate Rolls Royce Tyne engine with Pratt\&Whitney ST40M marine gas turbine engine, together with developing and implementing the afferent electronics tailored for this specific application. The chosen configuration of the system has proved its compatibility with the given naval requirements, also being easily adaptable and customisable for similar applications

\section{Acknowledgement}

The work presented herein was funded by the Operational Programme Human Capital of the Ministry of European Funds through the Financial Agreement 51675/09.07.2019, SMIS code 125125.

\section{References}

[1] Y.G. LI , P. NILKITSARANONT: Gas Turbine Performance Prognostic for ConditionBased Maintenance, Applied Energy 86, no. 10 (2009): 2152-2161.

[2] P. LASKOWSKI: Damages to Turbine Engine Components, Scientific Journal of Silesian University of Technology. Series Transport 94 (2017): 111-121

[3] D. BURNES, A. CAMOU: Impact of Fuel Composition on Gas Turbine Engine Performance, Journal of Engineering for Gas Turbines and Power, Vol. 141, no. 10 (2019).

[4] GH. SAMOILESCU, D. IORGULESCU, R. MITREA, L. D. CIZER: Propulsion Systems in Marine Navigation, International Conference KNOWLEDGE-BASED ORGANIZATION, Vol. 24, no. 3 (2018): 78-82.

[5] Rolls-Royce Engines: Tyne - Graces Guide, Gracesguide.Co.Uk, 2019, https://www.gracesguide.co.uk/Rolls-Royce Engines: Tyne.

[6] P\&W to Power Norwegian Navy "Skjold" Patrol Boats, Defense-Aerospace.Com, 2019, http://www.defense-aerospace.com/articles-view/release/3/32064/p\%26w-turbinesfor- $\% \mathrm{E} 2 \% 80 \% 98$ skjold $\% \mathrm{E} 2 \% 80 \% 99$-boats-(jan.-20).html.

[7] M. BORZEA, GH. FETEA, R. CODOBAN: Implementation and Operation of a Cogeneration Plant for Steam Injection in Oil Field, Volume 7: Education; Industrial and Cogeneration; Marine; Oil and Gas Applications, 2008.

[8] J.M. BINNS, M.J. JOBY: Electronic Control of Marine Gas Turbine Engines, IFAC Proceedings Volumes 6, no. 3 (1973): 523-533.

[9] B. MACISAAC, R. LANGTON: Marine Propulsion Systems, Gas Turbine Propulsion Systems, 2011, 195-225.

[10] F. NICULESCU, A. SAVESCU: Aspects Regarding the Control and Regulation of an Industrial Turbine, 2019 11Th International Symposium on Advanced Topics in Electrical Engineering (ATEE), 2019.

[11] C.G. HODGE: The Integration of Electrical Marine Propulsion Systems, International Conference on Power Electronics Machines and Drives, 2002. 